\title{
Where should livestock graze? Integrated modeling and optimization to guide grazing management in the Cañete basin, Peru
}

\author{
Perrine Hamel ${ }^{1 *}$, Genowefa Blundo-Canto ${ }^{2,3}$, Virginia Kowal ${ }^{1}$, Benjamin P. Bryant ${ }^{1}$, Peter L. Hawthorne ${ }^{4}$ and \\ Rebecca Chaplin-Kramer ${ }^{1,4}$ \\ ${ }^{1}$ Natural Capital Project, Woods Institute for the Environment, Stanford University, USA \\ 2 Decision and Policy Analysis Research Area, International Center for Tropical Agriculture, Lima, Peru \\ ${ }^{3}$ CIRAD, UMR Innovation, Univ. Montpellier, Montpellier, France \\ ${ }^{4}$ Natural Capital Project, Institute on the Environment, University of Minnesota, USA
}

\begin{abstract}
Integrated watershed management allows decision-makers to balance competing objectives, for example agricultural production and protection of water resources. Here, we developed a spatially-explicit approach to support such management in the Cañete watershed, Peru. We modeled the effect of grazing management on three services - livestock production, erosion control, and baseflow provision - and used an optimization routine to simulate landscapes providing the highest level of services. Over the entire watershed, there was a trade-off between livestock productivity and hydrologic services and we identified locations that minimized this trade-off for a given set of preferences. Given the knowledge gaps in ecohydrology and practical constraints not represented in the optimizer, we assessed the robustness of spatial recommendations, i.e. revealing areas most often selected by the optimizer. We conclude with a discussion of the practical decisions involved in using optimization frameworks to inform watershed management programs, and the research needs to better inform the design of such programs.
\end{abstract}

\section{Keywords}

grazing management; watershed services program; optimization; InVEST models

\section{Code availability}

The InVEST seasonal water yield and sediment models are available from the open-source software suite InVEST: https://naturalcapitalproject.stanford.edu/invest/. Inputs to the InVEST models and key outputs are publicly available at: http://doi.org/10.5281/zenodo.3369896.

The Rangeland production model was developed in Python using the Century model, which is freely available by request from Colorado State University. All source code and documentation for the rangeland production model, including scripts and sample inputs to run the model for users who have obtained Century, are publicly available at: https://doi.org/10.5281/zenodo.572043.

Python scripts and data to reproduce the spatial optimization analysis are publicly available at: https://doi.org/10.5281/zenodo.3366381.

\footnotetext{
Correspondence:

Contact P. Hamel at perrine.hamel@stanford.edu

Cite this article as:

Hamel, P., Blundo-Canto, G., Kowal, V., Bryant, B.P., Hawthorne, P.L. \& Chaplin-Kramer, R.

Where should livestock graze? Integrated modeling and optimization to guide grazing management in the Cañete basin, Peru

Socio-Environmental Systems Modelling, vol. 1, 16125, 2019, doi:10.18174/sesmo.2019a16125

This work is licensed under a Creative Commons Attribution-NonCommercial 4.0 International License.
} 


\section{Introduction}

Throughout the world, there is a growing interest in investment in watershed services (IWS) programs that benefit both local populations and the environment (Abell et al., 2017). Given the complexity of the socioecological systems in which these efforts are embedded, interdisciplinary science approaches are often needed to inform policy. For example, IWS projects require a diversity of expertise ranging from social sciences to natural sciences, e.g. economics, policy analyses, hydrology, ecology, or agronomy. Expert knowledge in these fields needs to be further integrated with local stakeholder knowledge in order to reliably propose and implement policies that achieve stakeholders' objectives.

One approach to combine the various contributions of stakeholders and experts is to develop "optimal" spatial scenarios that integrate biophysical modeling and formal representation of stakeholder preferences (Bekele \& Nicklow, 2005; Cibin \& Chaubey, 2015; Pennington et al., 2017; Seppelt \& Voinov, 2002). These scenarios take the form of maps specifying where different interventions should be undertaken on a landscape. They can be used to explore possible futures within a participatory process, or to identify a single "best" scenario using precisely specified problem formulation.

Despite the importance of grazing impacts on ecosystem services (Petz et al., 2014), applications of spatial optimization methods for grazing management are scarce. Extending such optimization approaches to hydrologic services (sediment retention and baseflow enhancement) is even more limited: either studies use coarse global datasets that are not adequate for local management (e.g. Petz et al. 2014), or they use local data that require extensive field work (Ford et al., 2012). Yet livestock grazing occupies $30 \%$ of lands globally (Herrero et al., 2013) and the potential trade-offs between land-use intensification and water regulation must be acknowledged. Therefore, there is a need for simple physics-based approaches to provide information on grazing and ecosystem services and support local watershed management.

In this paper, we describe our experience integrating hydrological and grazing modeling, assessment of stakeholder interest, and formal optimization in support of an IWS program. We developed this approach in the context of watershed management in Peru, where a law ratified in 2014 "promotes, regulates and supervises the mechanisms that reward water-related ecosystem services generated through voluntary agreements, which determine interventions for the conservation, restoration and sustainable use that guarantee the permanence of ecosystems" (Art. 1, Law 302151). The regulatory framework of the law provides specific guidelines for design and operationalization of IWS mechanisms, defining the roles of different actors and the participation of public entities. This favorable legal and regulatory framework is expected to boost the design and implementation of IWS programs in the country.

The objective of this study is to provide an analytic framework and computational workflow that can support IWS programs like the one being implemented in the Cañete basin. In this particular context, the interventions considered include types and location of grazing activities, with the objectives to balance the provision of hydrologic ecosystem services (sediment retention and baseflow enhancement) with maintaining or increasing livestock production. In the following sections, we present an overview of the Cañete IWS program and the modeling framework used to assess the effect of grazing management on livestock and hydrologic services (Section 2), the model outputs, including the optimal landscapes under distinct assumptions (Section 3), and a discussion of the robustness of our results and policy implications (Section 4).

\section{Methods}

\subsection{Overview}

Our analysis integrates new and existing ecosystem service models within an optimization routine to identify a suite of optimal grazing management strategies, each reflecting different priorities placed on livestock production and hydrologic services. The approach comprises three steps (Figure 1). First, we model the effects

\footnotetext{
${ }^{1}$ Law in Spanish: http://www.minam.gob.pe/wp-content/uploads/2014/06/ley 302105 MRSE.pdf; Description in English: https://ciat.cgiar.org/outcome/first-peruvian-law-established-for-ecosystem-services-update-2016/
} 
of grazing interventions (various livestock types and densities) on livestock production and hydrologic services (sediment retention and baseflow contribution) across the Cañete watershed. Next, we use an optimization routine to generate multiple scenarios, each corresponding to a particular prioritization between objectives. Finally, we interpret these results in light of modeling uncertainties and economic and policy needs.

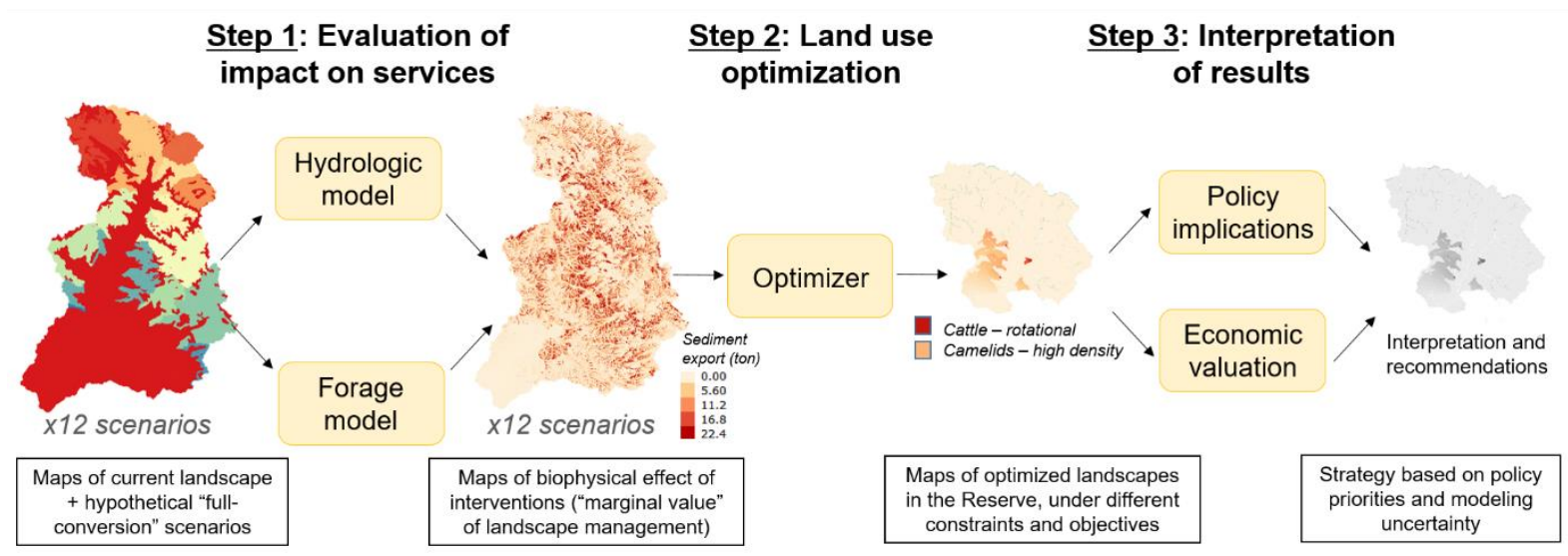

Figure 1: Overview of the modeling approach in the Cañete watershed. The three steps are: evaluation of impact on services (hydrologic and livestock models); landscape optimization under biophysical objectives; and interpretation of results for policy.

\subsection{Background on the Cañete watershed management program}

The Cañete watershed (Figure 2), located in west Peru, covers an area of 6,192 $\mathrm{km}^{2}$ with an elevation ranging from sea level to 4,429 $\mathrm{m}$. The climate is arid in the lower areas, with precipitation averaging $17 \mathrm{~mm} / \mathrm{yr}$, and changes to cold semi-arid in the upper areas ( 1000 mm /year). Major land uses are urban and agriculture (19\%

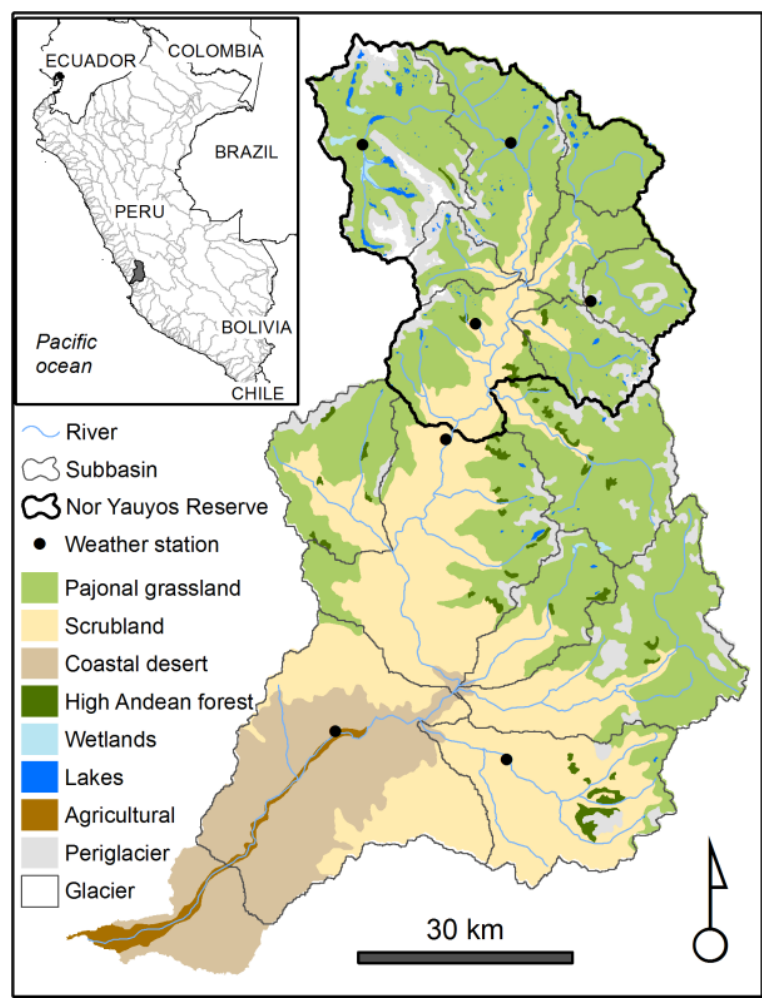

Figure 2: Overview of the Cañete watershed with major land use types and subwatershed delineation. The Nor YauyosCochas Landscape Reserve is located in the northern portion of the watershed. of the basin, predominantly in the lower areas), tropical alpine grassland (páramo; $14 \%$ of the watershed area), and shrubland (29\% of the watershed area). In the Northern districts, the Nor Yauyos-Cochas Landscape Reserve was established by the rural communities and local institutions in 2001 to protect diversity of flora and fauna in the high Andes (see location in Figure 2). With a surface of 221,268 ha, of which $\sim 62 \%$ belongs to the Upper Cañete watershed (Nor Yauyos), it is one of the two landscape reserves in Peru. As a reserve, it recognizes the close interaction between humans and nature in the area and allows sustainable direct use, exploitation and extraction of natural resources. The most prevalent agricultural activity in the Reserve is livestock grazing of cattle, sheep, and camelids (llamas and alpacas), which is a major source of income for local populations.

Since 2010, the area has been studied to design and implement an IWS program ('Reward Mechanism for Water-Related Ecosystem Services') (Quintero et al., 2013; Tristán Febres et al., 2018). The targeted areas have seen an increase in cattle grazing, which is typically associated with soil compaction, the potential deterioration of water retention, and an increase in soil erosion and runoff (Francesconi et al., 2018). It is therefore expected that the management of these grasslands would be improved with 
incentives that modify grazing practices by promoting different types of animals (either cattle, sheep, or camelids), different stocking densities, and allowing for rotational grazing. The aim of the program is to promote grazing management practices that prevent negative impacts on hydrologic services so that agricultural development can thrive with a minimal effect on downstream water use. Important hydrologic services for downstream users are the supply of baseflow (for hydropower production, downstream irrigation, and domestic use), and sediment retention (Quintero et al., 2013). Like most programs in Peru, the IWS program has an explicit livelihood improvement goal and has received attention by policy-makers and scientists (Quintero et al., 2013; Stern \& Echavarría, 2013; Tristán Febres et al., 2018).

\subsection{Scenarios of grazing management}

We assessed a total of twelve livestock management scenarios, in addition to the baseline where no grazing is allowed (i.e. current land use land cover, grassland, assuming no removal of biomass by grazing animals). The scenarios were defined using results from participatory workshops on conservation and development priorities in the targeted communities (Tristán Febres et al., 2018). They characterize the main management strategies possible in the region, in recognition of stakeholder interests, which are more focused on understanding broad trade-offs between these different strategies than prescribing an exact grazing plan for each landholder.

The twelve scenarios represent each possible combination of: animal types (cattle, sheep, and camelids), stocking density levels (high and low), and rotation schedules (continuous and rotational grazing). For simplicity, we considered that grazing interventions could only be applied on grassland, i.e. landcover types "pajonal de puna", "pajonal/cesped de puna", and "herbazal de tundra", and did not assess interventions where animals of different types grazed together. We derived stocking density interventions from recommended stocking densities in the area, which were locally derived by ecosystem managers familiar with the local forage resource and grazing practices (Huanca Palomino, 2015). Continuous grazing scenarios contained grazing during all months of the year at these stocking densities; rotational grazing scenarios contained grazing during half of the months of the year, at doubled densities (relative to values in Table 1).

Table 1: Stocking density interventions tested in optimization framework, as defined by Huanca Palomino (2015) as recommended sustainable carrying capacities for the study area. All values are in animals per ha. For other animal inputs, see Supplementary Material B.

\begin{tabular}{ccc}
\hline Animal type & Low density & High density \\
\hline Cattle & 0.2 & 1 \\
Camelids & 0.3 & 2 \\
Sheep & 0.2 & 3 \\
\hline
\end{tabular}

\subsection{Hydrological modeling}

\subsubsection{Baseflow model}

We used the InVEST seasonal water yield model (Sharp et al., 2019) to assess baseflow in the different scenarios. The tool computes a simple index that estimates the relative contribution to baseflow from each pixel on the landscape. For example, a pixel with a value of 1.5 contributes $50 \%$ more to baseflow than a pixel with a value of 1 (Supplementary Material A for model description). The model relies on the SCS-Curve Number method for estimating surface runoff (NRCS-USDA, 2004) and crop coefficients (Kc) for estimating actual evapotranspiration (Allen et al., 1998).

The model was applied to the Cañete basin in its simplest form, which computes the water budget for each pixel assuming that infiltrated water cannot be evapotranspired by downgradient pixels - i.e. effectively contributes to baseflow. While this simplifies the baseflow generation processes, the index is used as a proxy for baseflow, representing the difference between local precipitation, evapotranspiration, and surface runoff. To validate the approach, we compared baseflow estimates to those of a calibrated hydrologic model (Francesconi et al., 2018), which indicated that the InVEST model satisfactorily explained the variance in baseflow at the subwatershed scale (see Supplementary Material for details). 


\subsubsection{Sediment model}

We used the InVEST sediment model to compute soil loss and sediment transport across a landscape (Sharp et al. 2019). It relies on the universal soil loss equation, and a transport index, the sediment delivery ratio, which provides spatially-explicit estimates of the proportion of eroded soil that reaches the stream (i.e. which is not retained on the land). Inputs include rasters of erosivity, erodibility, a digital elevation model, and land use land cover with associated erosion factors ( $C$ and $P$ factors, representing the cover-management and practice, i.e. grazing management in this case study; see Supplementary Material A for data sources). It outputs sediment export for each pixel over the landscape. The model has been applied successfully in a range of geographies (Hamel et al. 2017), providing confidence in its estimates of relative contributions to sediment export in a watershed. It was used in this study with default parameters in the absence of sediment load observations for model calibration data.

\subsubsection{Effect of grazing on hydrological services}

Literature on the effect of grazing on hydrology remains scarce. While the qualitative effects are generally accepted (grazing decreases infiltration through soil compaction and increases erosion through reducing ground cover), quantifying their effects on hydrologic services is challenging (see review in Supplementary Material A3). For the present study, we developed an empirical approach to represent grazing scenarios based on values of above-ground biomass (Section 2.5). These values were converted to ground cover (a value between 0 and 1 ) based on empirical data from Paruelo et al. (2000).

In the InVEST seasonal water yield model, the only parameter affected by grazing management is the curve number (CN). Of note, crop coefficients Kc could also be changed but evapotranspiration is shown to be minimally impacted in the Andes (Supplementary Material A3). We derived the minimum and maximum CN values from the literature, corresponding to absence of grazing (minimum value, $\mathrm{CN}_{\min }$ ) and high impact grazing (maximum value, $\mathrm{CN}_{\max }$ ), respectively. We used a linear interpolation on ground cover to derive intermediate parameter values corresponding to each ground cover estimate (Table 2). Next, to account for soil compaction occurring with hooved animals, we also altered curve number values by modifying soil groups: Under highintensity grazing for cows and sheep, soil groups were moved one class down (from A to D, except for group D), corresponding to a decrease in soil hydraulic conductivity.

For the InVEST sediment model, a similar approach was used for sediment modeling, where the C-factor was varied linearly between its minimum and maximum values, $C_{\min }$ and $C_{\max }$. (The $\mathrm{C}$-factor is an empirical factor representing cover and management, therefore related to ground cover.) For high intensity grazing with cattle and sheep, sediment export are further increased by $20 \%$, reflecting the effect of hooves on soil erodibility (Table 2).

Table 2: Parameterization of grazing management interventions in the hydrologic models. Min and max subscripts indicate the minimum and maximum values of the parameters corresponding to no grazing and high intensity grazing. GC stands for ground cover, a value between 0 and 1. GC is obtained from the biomass values based on the relationship developed by Paruelo et al. (2000): Biomass $=0.777 * G C-9.863$

\begin{tabular}{lll}
\hline & C-factor (Sediment retention) & CN* (Baseflow provisioning) \\
\hline No grazing & $\mathrm{C}_{\min }=0.01$ & $\mathrm{CN}_{\min }=[39,61,74,80]$ \\
Camelids, Sheep, & $\mathrm{C}_{\max }+\mathrm{GC}^{*}\left(\mathrm{C}_{\min }-\mathrm{C}_{\max }\right)$ & $\mathrm{CN}_{\max }+\mathrm{GC}^{*}\left(\mathrm{CN}_{\min }-\mathrm{CN}_{\max }\right)$ \\
and cattle & With $\mathrm{C}_{\min }=0.01 \mathrm{and} \mathrm{C}_{\max }=0.1$ & With $\mathrm{CN}_{\min }=[39,61,74,80]$ and $\mathrm{CN}_{\max }=[68,79,86$, \\
& & $89]$ \\
& $\begin{array}{l}\text { For high intensity grazing with cattle } \\
\text { and sheep, result is further increased by } \\
20 \%\end{array}$ & $\begin{array}{l}\text { For high intensity grazing with cattle and sheep, soil } \\
\text { hydrologic group is moved one class (representing a } \\
\text { decrease in hydraulic conductivity) }\end{array}$ \\
\hline
\end{tabular}

${ }^{*} \mathrm{CN}$ values are given for the four hydrologic groups $[\mathrm{A}, \mathrm{B}, \mathrm{C}, \mathrm{D}]$ used in the SCS-CN method 


\subsection{Rangeland production modeling}

The rangeland production model developed for this study is a dynamic linkage of the Century ecosystem model (Parton et al., 1988) and the GRAZPLAN ruminant physiology model (Freer et al., 2012). It captures the feedbacks from grazing intensity to forage production and nutrient content, and back to livestock intake and liveweight performance (Supplementary Material B). The model predicts forage and livestock production from climate, soil, vegetation composition, animal breed, and grazing management (intensity and duration of grazing events) on each point of the landscape. A full description of the model and data sources is provided in Supplementary Material B.

We ran the model separately for each unique combination of soil, land use, and climate, also known as hydrologic response unit (HRU) in the study area. HRU boundaries were derived from a previous modeling effort with SWAT (Soil and Water Assessment Tool) conducted by Francesconi et al. (2018). Climate inputs were taken from the weather station located closest to the centroid of the subwatershed containing HRUs (Figure 2). Soil inputs for each subwatershed were calculated as the average values from high-resolution (100m) soil data (Francesconi et al., 2018).

\section{Rotational schedules}

While continuous grazing scenarios included grazing at all months of the year at the densities given in Table 1, rotational scenarios simulated grazing at doubled densities during half of the months of the year (keeping total animal-unit-months constant). A common practice in the region is to graze animals in one area for approximately four months at a time, then allow a four-month rest period (Instituto de Montaña, 2015). Preliminary analysis of rotational grazing schedules demonstrated that grass biomass and animal weight gain did not differ substantially between different months chosen for grazing vs. rest periods. That is, the model predicted similar yearly average forage biomass and livestock weight gain in simulations containing grazing in months 1-4 as in those containing grazing in months 5-8. We therefore modeled standing biomass and livestock weight gain in rotational grazing scenarios by running the rangeland production model for two complementary (opposite months) grazing schedules of 4-month duration and taking the average of the two simulations. We took the average over the $1994-2009$ period to ensure that the two rotated schedules contained the same total number of months of grazing. To ensure that the total number of simulated animals at any given month was the same for continuous and rotational scenarios, we doubled the density of animals in rotational scenarios, while halving the duration of grazing.

\subsection{Optimization approach}

The optimization approach aims to develop a suite of landscapes, or intervention portfolios, populating the efficiency frontier between each service (livestock productivity and hydrologic services). To do this, we calculate the "marginal value" of each intervention for each of the 2,926 HRUs in the landscape (marginal values for hydrologic variables are calculated as the average of pixel contained in one HRU). Marginal values are used in an integer programming problem that is iterated through different objective weight values to generate an intervention portfolio corresponding to each weight combination.

\subsubsection{Marginal values}

\section{Marginal values of hydrologic variables}

We ran the InVEST hydrologic models for the baseline landscape and the twelve grazing management scenarios, with hydrologic parameters adjusted as described in Section 2.4.3. We then computed marginal values of the sediment retention and baseflow services, for each pixel, as the difference between the scenario and baseline values:

$$
\begin{aligned}
& M V_{m, p}^{\text {sed }}=S E D_{p}^{m}-S E D_{p}^{\text {baseline }} \\
& M V_{m, p}^{b f}=B F_{p}^{m}-B F_{p}^{\text {baseline }}
\end{aligned}
$$

where $M V_{m, p}^{\text {sed }}$ and $M V_{m, p}^{b f}$ are the marginal values for sediment retention and baseflow, respectively, on pixel $p$, for each management scenario $m(m=1, \ldots, 12)$; SED is the sediment export (ton/yr) and $B F$ is the baseflow 
contribution $(\mathrm{mm})$ computed by the InVEST models. These pixel-level values were summed to get HRU-level marginal values (see Section 2.6.2). Hereafter, the HRU is the spatial decision unit, and is indexed by $i$.

\section{Marginal values of livestock productivity}

For each grazing scenario, we calculated livestock productivity as the average weight gained by the livestock herd in one year, or marginal value of livestock production, $M V_{m i}^{l s}$. We first calculated for each subwatershed the average weight gained by the herd on a per-hectare basis. Next, for each HRU contained in the subwatershed, we multiplied this value by the area of the HRU in hectares to get total average predicted weight gain in one year for that HRU.

While this quantity gives a standardized metric of productivity across animal types, we recognize that a given amount of weight gained by one animal type is likely to be of different value than the same amount gained by a different animal type. To account for these differences in value between animal types, we attempted to implement a method for economic valuation based on the results of household surveys conducted in the priority districts in 2015. Because this attempt was unsuccessful (see details in the Discussion), we decided to use the biophysical variable of animal weight as the explicit optimization variable and allow stakeholders to bring in additional knowledge to value the changes, rather than introduce false precision through a tenuous monetization approach.

\subsubsection{Optimization algorithm}

The optimization problem aims to identify, for each landscape unit, the grazing intervention that maximizes a landscape-wide objective function based on the three variables of interest (baseflow supply, sediment retention, and livestock production). The routine is applied to the individual HRUs contained in the subwatersheds that form part of the Reserve (see Figure 2). We use HRUs rather than pixels as optimization units for two reasons: there are less of them (2926 HRUs vs. 760,000 pixels), and the spatial extent is more adapted to grazing management recommendations (recommending practices at the scale of the pixel, $90 \mathrm{~m}$-side squared parcels, would not be practical nor robust).

The objective function is a linear combination of the three marginal values (see Section 2.6.1), where weights reflect willingness to trade-off a relative increase in one service at the expense of another. Mathematically, for any given objective weight combination, the solver maximizes the following expression:

$$
\sum_{m} \sum_{\mathrm{i}} x_{m i}\left[w^{s e d} V_{m i}^{s e d}+w^{b f} V_{m i}^{b f}+w^{l s} V_{m i}^{l s}\right]
$$

where $m$ indexes each management scenario; $i$ indexes the landscape decision units (HRUs); the $w^{o b j}$ terms are the weights for each of the objectives: sediment, baseflow, and livestock productivity values, respectively; and $V_{m i}^{o b j}$ are the corresponding normalized marginal values (see Eq. 3) for each of the objectives in HRU $i$ under management scenario $m$. The decision variable, $x_{m i}$, is a binary variable that takes the value 1 if management $m$ is assigned to $\mathrm{HRU} i$, and 0 otherwise (no grazing intervention).

Marginal values are initially expressed in the units of the objective (e.g. kg liveweight gained per year, tonnes of sediment per year) and range from large negative to large positive values. To use them in the optimization process, we rescale them to each be between zero and one, with the following equation:

$$
V_{m i}^{o b j}=\frac{M V_{m i}^{o b j}-M V_{M I N}^{o b j}}{M V_{M A X}^{o b j}-M V_{M I N}^{o b j}}
$$

Here $M V_{m i}^{o b j}$ is the HRU-level marginal value for the given objective, and $M V_{M I N}^{o b j}$ and $M V_{M A X}^{o b j}$ are the smallest and largest values for that objective measured across all management scenarios. Prior to applying Eq. 3, we multiplied the sediment marginal values by -1 so that normalized positive values (i.e. a minimum increase in sediment export) are desirable, consistent with the other objectives. Note that included in the set of marginal values is always a "no grazing" intervention, which is 1 for hydrologic objectives and 0 for livestock production.

This normalization can be interpreted as calculating the effect of each intervention relative to the maximum effect since the range $M V_{M A X}^{o b j}-M V_{M I N}^{o b j}$ is equal to $M V_{M A X}^{o b j}$ for the three objectives (with a precision of $0.001 \%$ : 
for the baseflow objective, the range is slightly higher but within $0.001 \%$ of $M V_{M A X}^{o b j}$, likely due to numerical errors). This interpretation is further discussed in Sections 3 and 4.

The optimization problem was implemented using the CVXOPT Python package (Anderson et al., 2004) and solved using the GLPK Python package. This solver chooses discrete interventions for each HRU such that the aggregate objective (Eq. 2) is maximized across implementation units.

\subsubsection{Exploration of optimal portfolios and uncertainty analyses}

We explored a range of objective weights $(0,0.1,0.3,0.5,0.7,0.9$, and 1 , for each objective weight, excluding redundant cases when weights are equal to each other) in order to develop a suite of portfolios that capture a range of preferences and help characterize tradeoffs between livestock productivity and water services. Each of these optimal solutions corresponds to a different portfolio of recommended grazing practices across the study area, conditional on the particular prioritization weighting. In addition, we produced a "modal" portfolio map, which displays the interventions most often chosen across all combinations of objective weights (the term "modal" referring here to the statistical mode, i.e. the value that occurs most frequently). We also calculated agreement maps, which display a value between 0 and 1 representing the proportion of scenarios that selected the most commonly chosen intervention. For example, if the optimizer recommended "low intensity camelid" as the best option for grazing on a particular HRU in $60 \%$ of the cases, the modal portfolio would show "low intensity camelid" for that HRU, and the agreement map would show a value of 0.6.

\section{Results}

\subsection{Optimal portfolios}

For quality control, we first consider the limiting cases where all weight is placed on one particular objective. In these cases, the only relevant information is contained in the marginal value maps for the service under consideration: for each $\mathrm{HRU}$, the optimizer simply picks the management scenario with the highest marginal value for that objective. Because grazing activities negatively impact hydrological services regardless of location, the optimizer finds that the "no grazing" option is optimal over the whole landscape when the hydrologic services are the only objectives. Conversely, because high-intensity cattle grazing yields the highest animal productivity according to the rangeland production model, this is the optimal activity over the whole landscape if animal productivity is the only objective.

Other combinations of objective weights represent the more interesting cases with multiple objectives. Given our choice to normalize the marginal values (see Section 2.6.2), objective weights indicate willingness to tradeoff relative changes in a service index compared to the maximum impact of the interventions. For example, with equal weights, a $5 \%$ increase in baseflow has the same importance as a $5 \%$ decrease in sediment export or a $5 \%$ increase in livestock productivity (all changes being relative to the possible range of impacts). Under this equal weighting, the optimal portfolio comprises a combination of high- and low-intensity cattle grazing, with and without rotation, in the upper areas, and the absence of grazing in the southern areas, where the trade-off with hydrological services was higher (Figure 3a).

When prioritizing hydrologic services, the optimal portfolio comprises more high-intensity cattle grazing with rotation, reflecting the positive role of the rotational grazing on the hydrologic services. This is exemplified in Figure $3 b$, representing a combination of weights favorable to hydrologic services (objective weights equal to $0.9,0.7,0.1$, for baseflow, sediment and livestock production, respectively). In this example, low intensity camelid grazing also appears in the central areas (Figure $3 \mathrm{~b}$ ), reflecting the lower impact of this activity on hydrologic services: the decrease in hydrological services under cattle grazing was high in these areas close to the stream, and camelid grazing provided a more optimal tradeoff (see Supplementary Material A1 for a map of current baseflow enhancement service). There are also larger areas without grazing in the southern parts of the Reserve, which means that adding livestock production in this area would diminish the value of the aggregate objective (a gain in livestock production would be offset by the loss in hydrologic services with the particular combination of weights). 
These tradeoffs can be visualized with frontier plots, such as the one represented in Figure 4. The shape of the curve characterizes the trade-off between the sediment retention service and livestock productivity. In this case, the steep slope for high livestock production scores indicates that gains in livestock production occur with a higher cost for the sediment score, as the livestock production gains increase. Conversely, in the lower range of livestock production values, up to about $4.5 \mathrm{e}+06 \mathrm{~kg}$ of yearly gain, there is little cost for the sediment score, which means that a significant livestock production can be achieved with relatively low impact on the sediment levels.

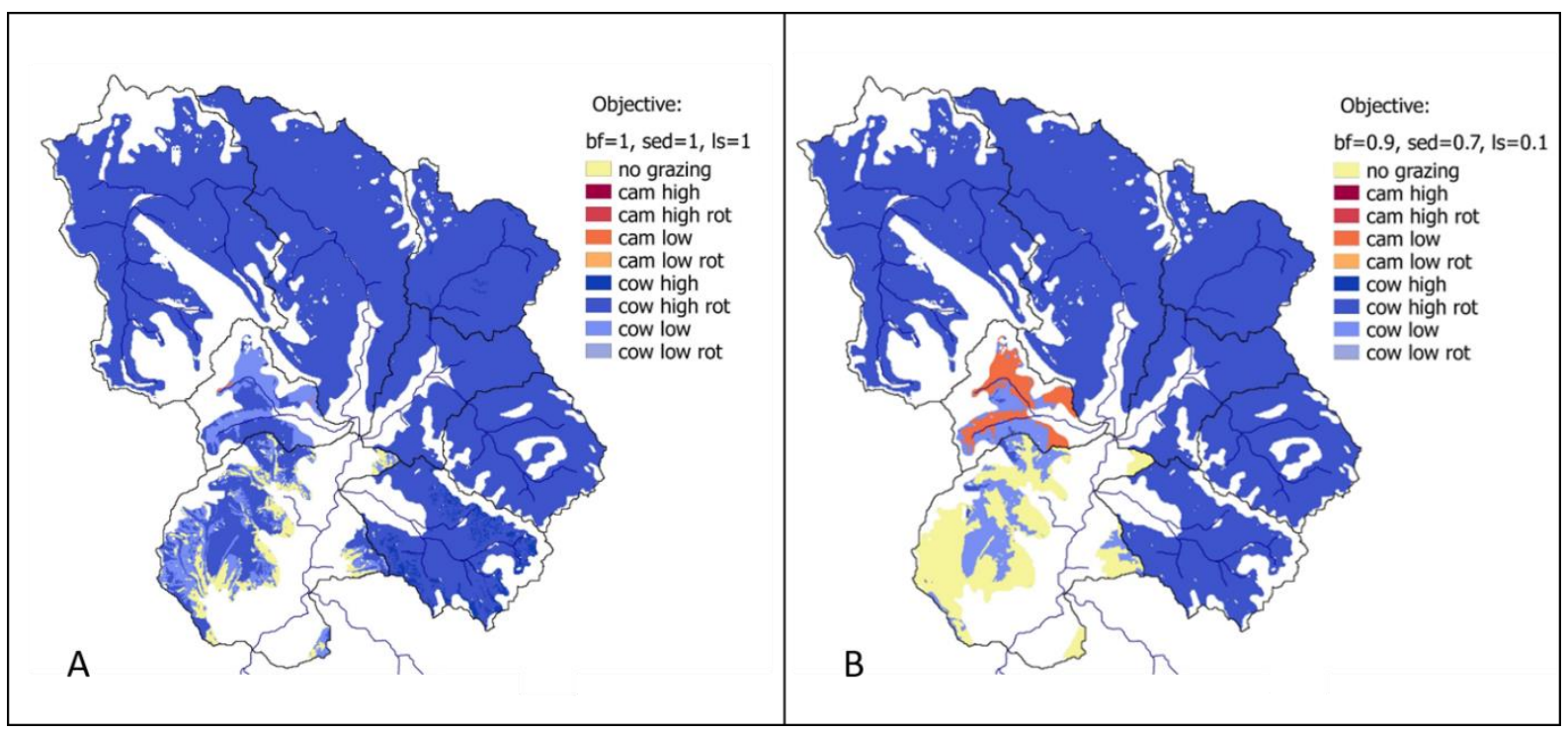

Figure 3: A) Optimal grazing management portfolio obtained with equal objective weights for the three services. B) Optimal grazing management portfolio obtained when prioritizing water services (objective weights equal to $0.9,0.7,0.1$, for baseflow, sediment and livestock production, respectively).

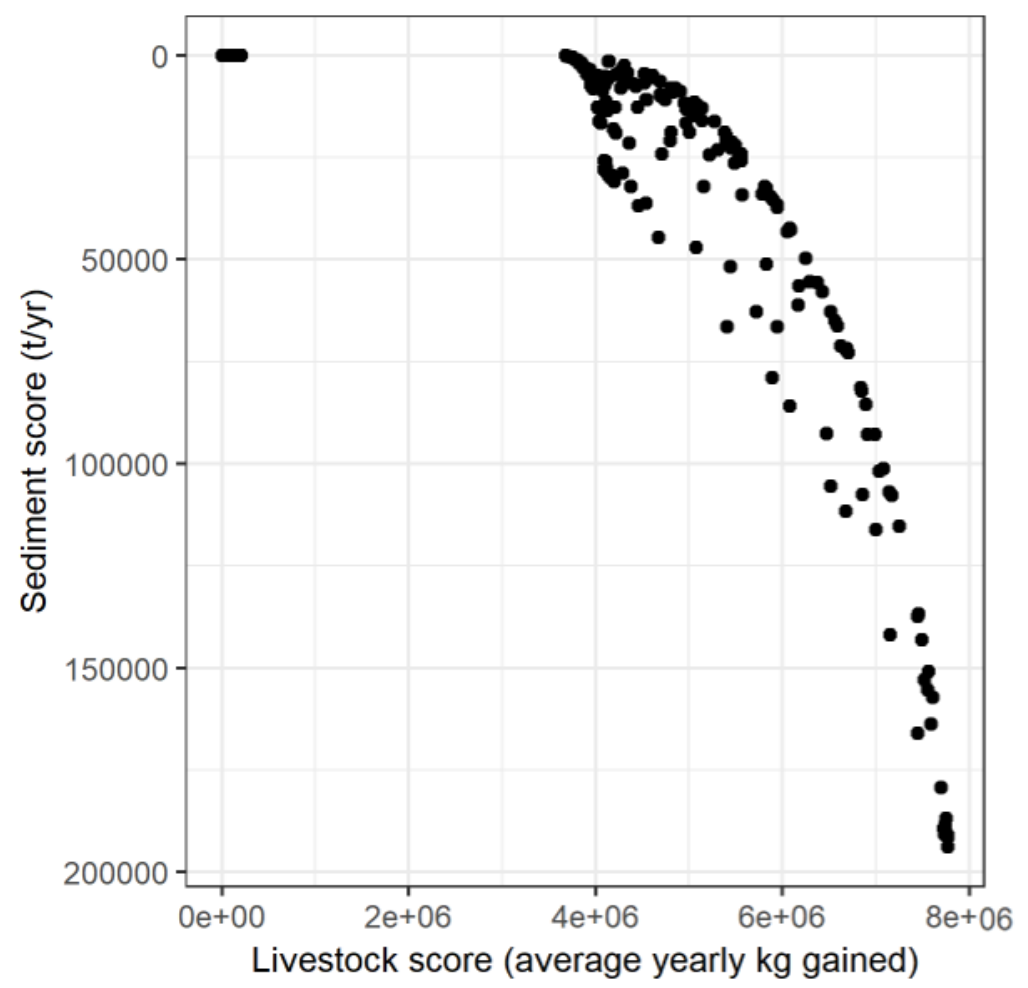

Figure 4: Frontier plot representing the tradeoffs between the sediment and livestock objective. Each point represents one combination of weights. Points that are interior to the frontier are those points where higher weight is given to the baseflow enhancement, the third objective that is not shown. 


\subsection{Agreement maps}

Stakeholders' preferences for different objectives can be assessed through elicitation processes. Recognizing the uncertainties inherent to such process, an alternate approach to distilling robust information is to identify which interventions are most commonly chosen across the range of possible preferences, together with the frequency of selection. This information is captured in the modal portfolio map and agreement map shown in Figure 5. Figure 5a indicates that high intensity rotational cattle grazing is the activity most often selected by the optimizer across the entire set of weight combinations, reflecting the high score of this intervention with regard to livestock productivity that outweighs its contribution to negative water impacts. In addition, the southwestern part of the Reserve was most often left without grazing, indicating that most of the grazing activities had high negative impacts at this location. Figure $5 \mathrm{~b}$ depicts the agreement frequency, and shows that the optimal choice for eastern parts of the landscape (cattle grazing) is generally consistent across weights, while the most appropriate intervention in the western portions is more sensitive to the objective weight combination.

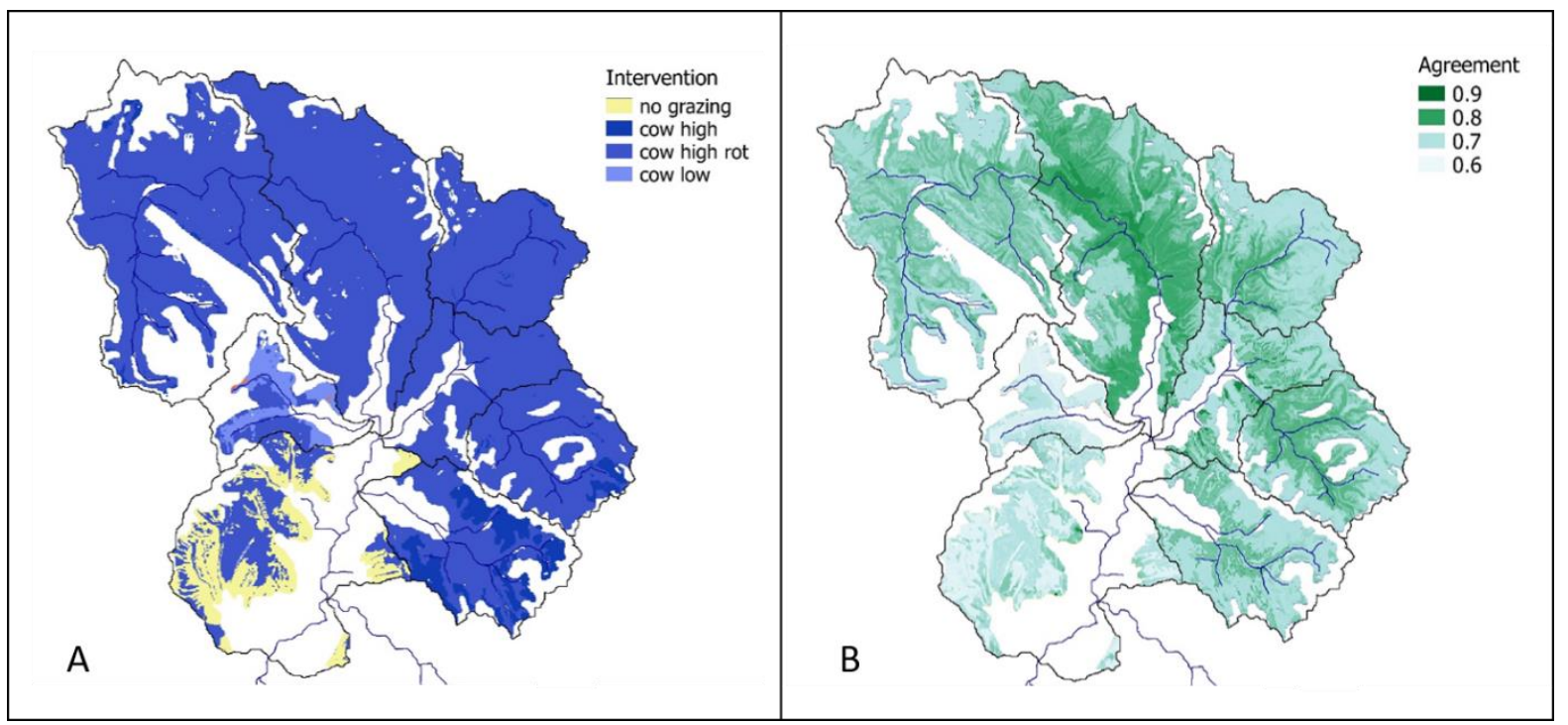

Figure 5: A) Map representing the interventions most often selected across all the combinations of objective weights. B) Level of agreement for the interventions represented in panel $A$.

\section{Discussion}

The goal of this study was to develop an approach to provide spatially-explicit recommendations on grazing management accounting for tradeoffs between grazing and hydrologic services. Our method is based on three steps: evaluating services, generating a suite of management plans optimized for a range of prioritization between outcomes, and interpreting results in light of uncertainties. Prior to the application of this method, a key step is the definition of the optimization problem, including for example the selection of grazing practices or optimization constraints, which we discuss in the final part of the discussion (Implications for management and future research).

\section{Strengths and limitations of the service evaluation}

Hydrologic services were assessed with the open-source InVEST software, where the effect of grazing was represented by a change in hydrologic parameters. Hydrologic models that are better able to capture underlying biophysical processes would improve future modeling efforts, although the development of such models remains limited by scarce ecohydrological knowledge (Bilotta et al., 2007; Hamel et al., 2018). Valuation of hydrologic services in terms of environmental (or economic) terms would also help contextualize the results, facilitating their communication to stakeholders. 
The effect of management practices on above-ground biomass and animal weights were represented by the rangeland production model developed for this study. Like previous efforts with globally available data (Petz et al., 2014), the model used major simplifications related to initial animal weights or assumptions for rotational grazing. Two modeling choices added uncertainty in the absolute value of modeled liveweight gain: first, the model does not simulate reproduction or death, and therefore liveweight gain may have been overestimated as energetic costs of reproduction and lactation were not included. In the opposite direction, liveweight gain was likely depressed by our choice to model animals near the age of maturity in the absence of more precise herd demographic information. Despite these limitations, the coupled model developed for this study was useful to represent relative impacts (for example, higher biomass and livestock productivity in the northern, wetter, subwatersheds).

A key decision related to livestock productivity was to express outputs in terms of animal liveweight gain, rather than economic gains for the owners. As mentioned in Section 2.6.1, this decision followed an unsuccessful attempt to value livestock productivity directly through economic gains (from byproducts and animal sale obtained in a local survey). Specifically, we calculated the net profit gained from one $\mathrm{kg}$ of animal at sale (i.e., when the animal is sold or slaughtered) or from animal byproducts such as meat or wool if sold directly from the producer. This dollar value, which accounts for differing profitability between animal types, could be used as an objective in the optimization routine. However, the survey data showed only a weak correlation $\left(r^{2}<0.23\right)$ between animal weights and economic gain for households, which suggests against relying on it within our formal optimization approach. Given that weight gain may be valued differently for different animals, additional work is needed in collaboration with local groups to understand how people in the region value livestock productivity.

\section{Strengths and limitations of the optimization approach}

The optimization was performed with an integer optimization algorithm aiming to maximize a linear combination of the three marginal values of services, over a variety of objective weight combinations. This analysis is transparent but the a priori selection of objective weights is not always possible nor advisable. Rather, exploring across weights should be seen as an instrumental step to generate solutions across the trade-off surface for consideration within a broader decision process, as opposed to focusing on one set of weights as the best combination for the landscape. Implementing such participatory process is still a research frontier but is increasingly recognized as a key step towards making optimization approaches more intuitive and relevant to decision-making (Smith et al., 2017; Voinov, 2017).

When the full range of possible prioritizations is included in the analytic process, frontiers and the bundles of services provided by each optimized landscape can be displayed in absolute and relative terms for more in-depth stakeholder consideration (Figures 3 and 4). The stakeholder group can then decide which of the landscapes provide acceptable levels of services, narrowing down the acceptable set of solutions. If stakeholders disagree about choices between particular landscape outcomes, the issue can be partially addressed by creating agreement maps presented in Section 3.2, which highlight interventions common across the range of optimized landscapes. In the case of Figure 5, combinations of weights spanning the full range of possible values were assessed, but a subset of those could be selected to represent, for example, a preference for hydrologic services. For example, stakeholders may not know exactly how much they value an improvement in hydrologic services over an improvement in animal weight, but they might know that they certainly don't value it three times as much. In that case, an analyst could re-generate the modal portfolio and agreement map, omitting all cases where hydrologic services received three or more times the priority of animal weight gain. This type of analysis allows one to characterize how robust policy recommendations are to prioritizations between services.

An alternate approach to develop weights for aggregating marginal values is through monetary valuation. In a market setting, the ratio between prices of different goods represent the willingness to exchange between those goods. Therefore, weights in the objective function effectively represent prices. While also laden with uncertainty, exercises in bounding valuation can at least serve as a means to constrain objective weight combinations that may be of interest. Stepping back even further, stakeholders will likely have contextual knowledge of processes and other objectives not captured in the formal framework that may help them relate specific portfolio compositions to their own priorities. We found that use of intermediate products such as marginal value maps can allow stakeholders to integrate the quantitative biophysical information in implicit ways. In these cases, there may technically be no need for the optimization-generated portfolios, though they 
arguably provide context for what is achievable and what quantified performance may be given up in search of other less quantified objectives.

\section{Implications for management and future research}

The approach presented here relies on a number of choices related to the representation of management decisions: units of marginal values (physical units rather than other welfare metrics), units of analyses (hydrologic units, HRUs, ranging from $<0.1 \mathrm{~km}^{2}$ to $244 \mathrm{~km}^{2}$ ), spatial constraints (e.g. on where animals should graze, based on current populations and district organization), or initial conditions (e.g. assuming that the baseline map with good quality pasture is a good reference, while some pasture areas may currently be degraded). Exploring how these choices affect intervention portfolios would improve the robustness of the analyses. As such, the results presented here are limited in scope and provide a starting point to inform landscape management. Interactive (or at least iterated) decision-aid tools may be useful to explore new scenarios in the future, with the possibility to change objectives or practical constraints. In practice, the development of such tools requires a close coordination between scientists and stakeholders with the opportunity to provide early results and iterate on the approach.

Uncertainty assessment and communication is often challenging in the type of analyses presented here, given the system complexity and multiple modeling steps. Some visualization techniques like the agreement maps presented here allow decision-makers to confront uncertainty explicitly. Other techniques include parallel plots to present multi-dimensional information for many scenarios, or the use of dynamic tools (e.g. webtools) that enable stakeholders to interactively explore the effect of individual sources of uncertainty (Weil, 2017). In general, engaging the conversation on uncertainty with stakeholders early in the project helps to focus efforts based on the types of uncertainty that both stakeholders and model developers consider as potentially significant.

In summary, several research areas could help improve the analyses presented here. First, filling knowledge gaps in ecohydrology will bring more confidence in the evaluation of services. The effect of grazing practices on hydrologic functions and on livestock productivity is still highly uncertain, especially in the Andes (Supplementary Material A3). Second, further development of participatory modelling approaches, engaging diverse stakeholders early on and through an iterative process, will improve the relevance of the modeling exercise. This also implies the ability to translate information in formats that allow adequate communication and interaction, such as comparative maps. Third, better guidance on uncertainty assessment will be key to provide robust recommendations based on optimization results. Transparent and feasible uncertainty assessment in ecosystem services analyses is still a relatively recent development (Hamel \& Bryant, 2017; Bryant et al., 2018) and the particular case of optimization analyses deserves more attention given many dimensions of model and preference uncertainty. Finally, the valuation approach, for hydrologic services and livestock productivity, would benefit from additional analyses. Future work may explore why the economic valuation approach to livestock productivity did not yield satisfying results, as well as possible approaches to value hydrologic services in monetary or non-monetary terms.

\section{Conclusions}

The paper presents a modeling approach to assess the impact of grazing management in the Cañete watershed. This type of analysis, which aims to combine a suite of ecological and social objectives and provide spatiallyexplicit recommendations, is of high relevance given the growing interest in IWS programs in Peru and around the world. Our biophysical and economic modeling efforts required a variety of simplifying assumptions amid scarce data, leading to uncertainties in the estimation of ecosystem services. These were partly addressed by computing agreement maps capturing the general trends in the selection of interventions given a range of preferences (i.e. objective weights). The optimization framework, including the selection of ecological objectives, spatial units, or additional constraints on grazing practices, was simplified in this proof-of-concept, but our experience also highlights the challenges involved in connecting modeling efforts to stakeholder relevance in data scarce environments. Iterative and participatory improvement of the scenarios and modelling approach are a way forward to develop policy-relevant recommendations. 


\section{Acknowledgements}

The authors acknowledge the CGIAR Research Program on Water, Land and Ecosystems (WLE) for funding this research.

\section{References}

Abell, R., Asquith, N., Boccaletti, G., Bremer, L., Chapin, E., Erickson-Quiroz, A., Higgins, J., Johnson, J., Kang, S., Karres, N., Lehner, B., McDonald, R., Raepple, J., Shemie, D., Simmons, E., Sridhar, A., Vigerstøl, K., Vogl, A. \& Wood, S. (2017). Beyond the Source: The Environmental, Economic and Community Benefits of Source Water Protection. Arlington, VA, USA.

Allen, R. G., Pereira, L. S., Raes, D., \& Smith, M. (1998). Crop evapotranspiration - Guidelines for computing crop water requirements. Rome, Italy.

Anderson, M., Vandenberghe, L., \& Dahl, J. (2004). CVXOPT: Python Software for Convex Optimization.

Bekele, E. G., \& Nicklow, J. W. (2005). Multiobjective management of ecosystem services by integrative watershed modeling and evolutionary algorithms. Water Resources Research, 41(10). https://doi.org/10.1029/2005WR004090

Bilotta, G. S., Brazier, R. E., \& Haygarth, P. M. (2007). The Impacts of Grazing Animals on the Quality of Soils, Vegetation, and Surface Waters in Intensively Managed Grasslands. Advances in Agronomy, 94, 237-280. https://doi.org/10.1016/S0065-2113(06)94006-1

Bryant, B. P., Borsuk, M. E., Hamel, P., Oleson, K. L. L., \& Schulp, C. J. E. (2018). Transparent and feasible uncertainty assessment adds value to applied ecosystem services modeling. Ecosystem Services, 33, $103-109$. https://doi.org/10.1016/J.ECOSER.2018.09.001

Cibin, R., \& Chaubey, I. (2015). A Computationally Efficient Approach for Watershed Scale Spatial Optimization. Environmental Modelling \& Software, 66(C), 1-11. https://doi.org/10.1016/j.envsoft.2014.12.014

Ford, H., Garbutt, A., Jones, D. L., \& Jones, L. (2012). Impacts of grazing abandonment on ecosystem service provision: Coastal grassland as a model system. Agriculture, Ecosystems \& Environment, 162, 108-115. https://doi.org/10.1016/j.agee.2012.09.003

Francesconi, W., Uribe, N., Valencia, J., \& Quintero, M. (2018). Modeling for management: a case study of the Caňete watershed, Peru. In M. Rivera, D, Godoy-Faúndez, A and Lillo-Saavedra (Ed.), Andean Hydrology (pp. 84-101). Boca Raton, FL: CRC Press.

Freer, M., Moore, A., \& Donnelly, J. (2012). The GRAZPLAN animal biology model for sheep and cattle and the GrazFeed decision support tool. Canberra, ACT.

Hamel, P., \& Bryant, B. P. (2017). Uncertainty assessment in ecosystem services analyses: Seven challenges and practical responses. Ecosystem Services, 24. https://doi.org/10.1016/j.ecoser.2016.12.008

Hamel, P., Riveros-Iregui, D., Ballari, D., Browning, T., Célleri, R., Chandler, D., Chun, K. P., Destouni, G., Jacobs, S., Jasechko, S., Johnson, M., Krishnaswamy, J., Poca, M., Pompeu, P. V., \& Rocha, H. (2018). Watershed services in the humid tropics: Opportunities from recent advances in ecohydrology. Ecohydrology, 11(3). https://doi.org/10.1002/eco.1921

Herrero, M., Havlík, P., Valin, H., Notenbaert, A., Rufino, M. C., Thornton, P. K., Blümmel, M., Weiss, F., Grace, D., \& Obersteiner, M. (2013). Biomass Use, Production, Feed Efficiencies, and Greenhouse Gas Emissions from Global Livestock Systems. Proceedings of the National Academy of Sciences, 110(52), 20888-20893. https://doi.org/10.1073/pnas.1308149110.

Huanca Palomino, O. (2015). Diagnostico agrostologico de la Reserva Paisajistica Nor Yauyos Cochas. Lima, Peru.

Instituto de Montaña. (2015). Diagnóstico Participativo para el Plan de Manejo de pastos y Agua de la comunidad de Miraflores, Yauyos, Lima. Elaborado en el marco de la implementación de las medidas robustas del proyecto: "Adaptación basada en Ecosistemas de Montaña". Huancayo.

NRCS-USDA. (2004). Chapter 10. Estimation of Direct Runoff from Storm Rainfall. In United States Department of Agriculture (Ed.), Part 630 Hydrology. National Engineering Handbook. United States Department of Agriculture. http://www.nrcs.usda.gov/wps/portal/nrcs/detailfull/national/water/?cid=stelprdb1043063:

Parton, W. J., Stewart, J. W. B., \& Cole, C. V. (1988). Dynamics of C, N, P and S in Grassland Soils: A Model. Biogeochemistry, 5(1), 109-131.

Paruelo, J. M., Lauenroth, W. K., \& Roset, P. A. (2000). Technical note : Estimating aboveground plant biomass using a photographic technique. Journal of Range Management, 53(March), 190-193. https://doi.org/10.2307/4003281

Pennington, D. N., Dalzell, B., Nelson, E., Mulla, D., Taff, S., Hawthorne, P., \& Polasky, S. (2017). Cost-effective Land Use Planning: Optimizing Land Use and Land Management Patterns to Maximize Social Benefits. Ecological Economics, 139, 75-90. https://doi.org/10.1016/j.ecolecon.2017.04.024

Petz, K., Alkemade, R., Bakkenes, M., Schulp, C. J. E., van der Velde, M., \& Leemans, R. (2014). Mapping and modelling tradeoffs and synergies between grazing intensity and ecosystem services in rangelands using global-scale datasets and models. Global Environmental Change, 29, 223-234. https://doi.org/10.1016/j.gloenvcha.2014.08.007

Quintero, M., Tapasco, J., \& Pareja, P. (2013). Diseño e Implementación de un Esquema de Retribución por Servicios Ecosistémicos Hidrológicos en la Cuenca del Río Cañete. 
Seppelt, R., \& Voinov, A. (2002). Optimization methodology for land use patterns using spatially explicit landscape models. Ecological Modelling, 151(2), 125-142. https://doi.org/10.1016/S0304-3800(01)00455-0

Sharp, R. S., Tallis, H. T., Ricketts, T., Guerry, A. D., Wood, S. A., Nelson, E., Ennaanay, D., Wolny, S., Olwero, N., Vigerstol, K., Pennington, D., Mendoza, G., Aukema, J., Foster, J., Forrest, J., Cameron, D., Arkema, K., Lonsdorf, E., Kennedy, C., Verutes, G., Kim, C. K., Guannel, G., Papenfus, M., Toft, J., Marsik, M., Bernhardt, J., Griffin, R., Glowinski, K., Chaumont, N., Perelman, A., Lacayo, M., Mandle, L., Hamel, P., \& Chaplin-Kramer, R. (2019). InVEST 3.5 User's Guide. Available at: http://data.naturalcapitalproject.org/nightly-build/invest-users-guide/html/.

Smith, R., Kasprzyk, J., \& Dilling, L. (2017). Participatory Framework for Assessment and Improvement of Tools (ParFAIT): Increasing the impact and relevance of water management decision support research. Environmental Modelling \& Software, 95, 432-446. https://doi.org/10.1016/j.envsoft.2017.05.004

Stern, M., \& Echavarría, M. (2013). Mecanismos de retribución por servicios hídricos para la cuenca del Cañete, Departamento de Lima, Perú. Mecanismos de Retribución por Servicios Hídricos del Perú. In EcoDecisión. Washington, D.C.

Tristán Febres, M., Blundo Canto, G., Cruz-García, G., \& Quintero, M. (2018). Competing uses and access to hydrological resources in upstream peasant communities of the Cañete River watershed, Perú. In A. Rivera Diago, A. GodoyFaundez, \& M. Lillo-Saavedra (Eds.), Andean Hydrology (pp. 1-20). Boca Raton.

Voinov, A. (2017). Participatory Modeling for Sustainability. In M. A. Abraham (Ed.), Encyclopedia of Sustainable Technologies (pp. 33-39). https://doi.org/10.1016/B978-0-12-409548-9.10532-9

Weil, C. (2017). Natural Capital Data Visualization - A toolbox to synthesize and visualize complex ecosystem services model outputs. Retrieved from https://github.com/charlottegiseleweil/natcap_viz_toolbox 